Clinical \& Experimental Epilepsy, UCL Institute of Neurology, Queen Square, London WC1N 3BG, UK. E-mail: Isander(a) ion.ucl.ac.uk).

COMMENT. Compared to the general population, people with epilepsy have a 15- to 19- fold increase in risk of drowning, according to this meta-analysis of published articles. The actual number of drownings in children is small, only 4 of the 15 articles involving predominantly children including deaths due to drowning. Inadequate supervision was a frequent factor. One previous study suggested that the relative risk of drowning in the bath is 96 for children with epilepsy compared to those without, and for drowning in a swimming pool is 23 (Diekema DS et al. Pediatrics 1993;91:612-616). One in 20 deaths from drowning was due to seizures (Ryan CA et al. CMAJ 1993;148:781-784).

\title{
GENETICS OF AUTOSOMAL DOMINANT PARTIAL EPILEPSY WITH AUDITORY FEATURES (ADPEAF)
}

Data from 24 previously published ADPEAF families with mutations in the leucinerich, glioma inactivated 1 gene (LGI1) were analyzed, in a study at Columbia University, New York. Penetrance is $67 \%$, it tends to be greater in families with more affected individuals, does not differ with gender, and may increase with advancing generation. (Rosanoff MJ, Ottman R. Penetrance of LGI1 mutations in autosomal dominant partial epilepsy with auditory features. Neurology Aug 19, 2008;71:567-571). (Dr Ruth Ottman, GH Sergievsky Center, Columbia Univcrsity, $630 \mathrm{~W} 168^{\text {th }}$ St, P\&S Box 16, New York, NY 10032. E-mail: ro6(a)columbia.edu).

COMMENT. Autosomal dominant (AD) partial epilepsy with auditory features, also known as AD lateral temporal epilepsy, is an idiopathic focal epilepsy syndrome manifested by auditory symptoms (humming, buzzing, or ringing, volume changes, specific songs or voices) or receptive aphasia. Ictal receptive aphasia is a sudden inability to understand language without general confusion. Mutations in the LGII gene located on chromosome 10 occur in approximately $50 \%$ of families with ADPEAF, but not in families with other familial temporal lobe epilepsies.

Symptomatic temporal lobe auditory seizures. Many examples of seizures secondary to temporal lobe tumor and manifested by auditory illusions and hallucinations are included in the classic book by Penfield W, and Jasper H (Epilepsy and the Functional Anatomy of the Human Brain. Boston; Little, Brown \& Comp. 1954;459-467). One patient, a housewife of 43 years, complained of ringing in the ears and of hearing voices or music, a song she had heard previously, an hallucination sometimes she described as a dream. Another, a girl aged 16 years, heard a lullaby that her mother used to sing to her as an infant. In some attacks she complained of a change in volume or fading away of sounds, considered an illusional seizure. Stimulation of the cortex in the superior gyrus of the left temporal lobe illicited hallucinations of voices, saying words, repeated music (accompanied by humming), and "There was singing" response. Penfield referred to these as "psychical seizures." In children, temporal lobe seizures often begin with a sense and look of fear, the child clinging to mother, although unable to describe a possible associated hallucination. 